\title{
CARDIOPULMONARY RESUSCITATION: A REVIEW OF 184 CASES AND SOME APPLICATIONS FOR FUTURE IMPROVEMENTS
}

\author{
C. S. BROWN, M.D., AND A. A. SCOTT, M.D., DIP.ANAES., F.R.C.P.(C) ${ }^{\circ}$
}

IN North AMERica, most medium sized and large hospitals with house staff have had some form of cardiac arrest team for approximately ten years. These teams, along with the more recent innovation of coronary care units, are said to have contributed significantly to a reduced mortality from acute myocardial infarctions in the hospital. There are many papers in the literature reporting mortality reduction by virtue of the availability of coronary care units, ${ }^{1,2}$ and there are a few reports of the performance of cardiac arrest teams. However, the reports of the cardiac arrest teams have been largely of a review variety and have not suggested possible changes to improve this type of service.

This paper will attempt to: (a) analyse results of data accumulated from cardiac arrest reports for one year, from November 1968 through October 1969, at the Toronto General Hospital, and $(b)$ offer some possible applications of the data to improvement of existing cardiac arrest team services.

\section{Methods and Materuals}

At the Toronto General Hospital, the standard American Heart Association Cardiopulmonary Arrest Form is filled out by the anaesthetist on the cardiac arrest team. In the period analysed there were 328 calls for the cardiac arrest team, and 184 reports were received. Many arrests occurred in the coronary therapy unit and a few in other areas, where monitoring is carried out by staff personnel 24 hours a day. Consequently, some of these arrests have not been reported, as resuscitation on patients in these areas could be effected without the services of the cardiac arrest team. Only those arrests for which the cardiac arrest team's services were requested have been included. In the case of patients arresting more than once, these episodes have been reported as separate arrests only if they occurred more than 24 hours apart. Even though only about 56 per cent of the arrests for which the team was called have been reported with sufficient information to include them in this report, it is felt that this number is large enough to warrant study. All reports submitted have been included, as this report is an attempt to evaluate a service based on clinical need.

The vast majority of calls for the cardiac arrest team are based on the observation of absence of pulse, absence of respiration, or both. Consequently, many patients for whom the team is called do not show any post-event electrocardiographic or other measurable changes which would indicate that they did in fact have a cardiopulmonary arrest. However, it is possible that the early detection

${ }^{\circ}$ Dr. Brown is at Union Memorial Hospital, Baltimore, Md. Dr. Scott is at the Toronto General Hospital.

Can. Anaes. Soc. J., vol. 17, no. 6, November 1970 
of alterations in vital signs by various hospital personnel has obviated many potential cardiopulmonary disasters. It is also possible that patients who have suffered from sudden life-threatening arrythmias have been reverted by cardiac compression and proper ventilation before the portable ECG monitor could be applied.

The data collected in this review are broken down into three basic groups:

1. Those patients on whom cardiac arrests were called, but who survived less than 24 hours (died $-\mathbf{D}$ ).

2. Those patients who survived the initial arrest or arrests for more than 24 hours, but who died in hospital (initial survivors - Is).

3. Those patients who were discharged well from hospital after the arrest (ultimate survivors - us).

Further analysis of the reports includes: $(a)$ location in hospital, $(b)$ age of patient, $(c)$ sex of patient, $(d)$ cause of arrest (if known), $(e)$ who recognized the problem, $(f)$ how the arrest was recognized (i.e. no pulse, no respirations, etc. $),(g)$ who initiated the resuscitation procedure, and $(h)$ time interval between recognition and initiation of cardiopulmonary resuscitation.

\section{RESULTS}

\section{Location}

Forty-five per cent of the arrests occurred in "acute areas." This is highly significant in that the number of patient days in these areas is very small in relation to the total number of patient days for the hospital.

The areas in Table I have been grouped according to the intensity of monitoring and/or staff surveillance. All patients in the coronary unit and most

TABLE I

LOCATION

\begin{tabular}{lrrrr}
\hline & D & IS & Us & \multicolumn{1}{c}{ Total } \\
\hline ER & 28 & 5 & 1 & $34(18.5 \%)$ \\
CCU & 20 & 5 & 4 & $29(15.8 \%)$ \\
C.V. ICU & 4 & 1 & 0 & $5(2.7 \%)$ \\
Other ICUS & 11 & 3 & 2 & $16(8.7 \%)$ \\
& & & & $-\overline{84}(44.5 \%)$ \\
Other & 71 & 17 & 12 & $100(55.5 \%)$ \\
Total & 134 & 31 & 19 & 184 \\
\hline
\end{tabular}

patients in the cardiovascular unit are monitored, while only a few are monitored in the emergency room and other intensive care areas. Virtually none of the patients outside these areas are monitored. Although statistical analysis shows no significant difference in the survival rate in the different areas, many successful resuscitations were carried out in areas such as the coronary unit, without calling for the services of the cardiac arrest team. In support of this is the fact that figures from coronary units have shown a decrease in mortality 
because of more immediate recognition and treatment of life-threatening arrhythmias.

Age

Age distribution is given in Table II. There appears to be no significant difference in survival between age groups. This agrees with the findings of Hollingsworth. ${ }^{3}$ However, here again these results may be distorted by the fact that many of the patients in the "coronary" age group (50-70 years) were located in the areas where continuous monitoring is carried out, and some of these patients have not been included in this report.

When patients are grouped above and below the age of 60 , there is a signifcantly larger number of immediate survivals under 60 . There was no significant difference in ultimate survival between the two groups.

TABLE II

AGE

\begin{tabular}{lrrrr}
\hline Years & D & IS & US & Total \\
\hline $10-19$ & 5 & 3 & 0 & $8(4.3 \%)$ \\
$20-29$ & 7 & 4 & 1 & $12(6.5 \%)$ \\
$30-39$ & 7 & 7 & 2 & $16(8.7 \%)$ \\
$40-49$ & 15 & 5 & 5 & $25(13.4 \%)$ \\
$50-59$ & 19 & 5 & 2 & $26(14.1 \%)$ \\
$60-69$ & 40 & 6 & 7 & $53(28.8 \%)$ \\
$70-79$ & 34 & 1 & 2 & $37(20 \%)$ \\
$80-89$ & 7 & 0 & 0 & $7(3.7 \%)$ \\
Total & 134 & 31 & 19 & 184 \\
\hline
\end{tabular}

Sex

Two-thirds of the arrest group were males, and this is statistically significant but unexplained. At the Toronto General Hospital, three times as many males as females are admitted to the coronary care unit. The inference that coronary artery disease is mainly an affliction of males is supported. There was no signifcant difference in either immediate or ultimate survival rate (Table III).

TABLE III

SEX

\begin{tabular}{lrrrr}
\hline Sex & D & Is & us & Total \\
\hline Male & 89 & 19 & 15 & $123(66.8 \%)$ \\
Female & 45 & 12 & 4 & $61(33.2 \%)$ \\
Total & 134 & 31 & 19 & 184 \\
\hline
\end{tabular}

\section{Cause of arrest}

It is interesting to note that in this study acute myocardial infarction and pulmonary oedema (the first two items in Table IV), which comprise the "cardiac" causes of arrest, accounted for over 50 per cent of the arrests. However, neither the initial nor the final survival rate was significantly different from survival in patients with all other diagnoses. 


\begin{tabular}{lrrrr}
\multicolumn{1}{c}{$\begin{array}{c}\text { TABLE IV } \\
\text { CAUSE }\end{array}$} & & & \\
\hline \multicolumn{1}{c}{ Cause } & $\mathrm{D}$ & Is & Us & Total \\
\hline Acute myocardial infarction & 61 & 9 & 9 & $79(43 \%)$ \\
Pulmonary oedema & 6 & 7 & 1 & $14(7.6 \%)$ \\
Pulmonary embolus & 7 & 0 & 1 & $8(4.5 \%)$ \\
Drug & 4 & 1 & 2 & $7(4.1 \%)$ \\
Anaesthetic & 0 & 0 & 2 & 2 \\
Haemorrhage & 4 & 1 & 0 & $5(2.1 \%)$ \\
Obstruction & 4 & 0 & 1 & $5(2.7 \%)$ \\
Other & 23 & 6 & 3 & $32(17.4 \%)$ \\
Unknown & 25 & 7 & 0 & $32(17.4 \%)$ \\
Total & 134 & 31 & 19 & 184 \\
\hline
\end{tabular}

This area of compilation is one of the most difficult to assess because often the reason for the arrest is not known. In cases where the immediate cause of arrest was listed as "unknown," there were no ultimate survivors.

\section{Recognition of arrest}

As is to be expected, most of the cardiac arrests were discovered by nurses. Patients in the group designated as "other" were either brought in by ambulance or had the arrest while being visited by family or friends, who summoned medical help.

There is a significant difference in survival in those patients found by nurses as compared to those recognized by all others (Table V). The reason for this is not clear, but the time lapse between the time of arrest and the actual finding of the patient may be a factor. Many of those patients found by doctors probably had premonitory signs of an emergency nature and consequently the physician was summoned by a nurse who recognized a potential problem.

TABLE $V$

RECOGNITION OF ARREST

\begin{tabular}{lrrrr}
\hline \hline Found by & D & Is & us & Total \\
\hline Nurse & 84 & 20 & 6 & $110(60 \%)$ \\
Physician & 42 & 9 & 10 & $61(33.2 \%)$ \\
Hospital assistant & 0 & 1 & 1 & 2 \\
Other & 8 & 1 & 2 & $11.1 \%(5.7 \%)$ \\
Total & 134 & 31 & 19 & 184 \\
\hline
\end{tabular}

How arrest was recognized

Many of the reports indicated more than one clinical sign, e.g. "no pulse with dilated pupils." The absence of pulse, or of pulse and respirations, was, as might be expected, the most common clinical sign by which an arrest was detected. Respiratory difficulty, as reflected in "agonal" breathing, and dilated pupils are not felt to be primary diagnostic features to be used in determining an arrest. Certainly, agonal breathing may call attention to the fact that a patient is in difficulty, and dilated pupils may sometimes indicate duration of extremis, but these in themselves do not constitute criteria for calling an arrest without first checking to see if the patient is indeed pulseless. 
The survival rates were not affected by the initial clinical sign or signs (Table VI).

\author{
TABLE VI
}

How ARrest was Recognized

\begin{tabular}{lrrrc}
\hline \hline How recognized & D & IS & US & Total \\
\hline No pulse & 46 & 16 & 7 & $69(37.5 \%)$ \\
No respiration & 15 & 5 & 3 & $23(12.5 \%)$ \\
Nopulse or respiration & 53 & 5 & 6 & $64(35 \%)$ \\
Monitor & 20 & 5 & 3 & $28(15 \%)$ \\
Total & 134 & 31 & 19 & 184 \\
\hline
\end{tabular}

\title{
Type of personnel initiating arrest procedure
}

The vast majority of resuscitations were initiated by either a physician or a nurse, with nurses being responsible for about half the initial actions. There were no ultimate survivors among those patients on whom resuscitation was initiated by personnel other than physicians or nurses ( Table VII).

Analysis by grouping physicians against all others reveals no significant difference, although almost twice as many ultimate survivors had resuscitation initiated by a physician.

TABLE VII

Type of Personnel Initiating Arrest Procedure

\begin{tabular}{lrrrr}
\hline \hline & $D$ & Is & US & Total \\
\hline Nurse & 65 & 14 & 7 & $86(46.5 \%)$ \\
Physician & 65 & 16 & 12 & $93(50.5 \%)$ \\
Hospital assistant & 1 & 0 & 0 & $1(0.5 \%)$ \\
Other & 3 & 1 & 0 & $4(2.5 \%)$ \\
Total & 134 & 31 & 19 & 184 \\
\hline
\end{tabular}

Time from discovery of arrest to initiation of resuscitation procedures

This area is all-important, as is reflected in Table VIII. Of those who initially survived, 90 per cent had resuscitation begun within two minutes. Also, of those patients who left hospital alive, 94 per cent had resuscitation begun within two minutes. Statistical analysis is not valid because of the small population on whom resuscitation commenced more than one minute after discovery.

TABLE VIII

Time From Discovery to Resuscitation

\begin{tabular}{lrrrr}
\hline \hline & D & Is & Us & Total \\
\hline 1 minute & 104 & 28 & 17 & $149(80.5 \%)$ \\
2 minutes & 20 & 1 & 1 & $22(12.1 \%)$ \\
3 minutes & 6 & 1 & 0 & $7(4.1 \%)$ \\
4 minutes & 1 & 1 & 0 & $2(1.1 \%)$ \\
5 minutes & 1 & 0 & 1 & $2(1.1 \%)$ \\
5 minutes & 2 & 0 & 0 & $2(1.1 \%)$ \\
Total & 134 & 31 & 19 & 184 \\
\hline
\end{tabular}




\section{Discussion}

The overall resuscitation rate at the Toronto General Hospital shows that 37.3 per cent of cardiac arrest patients survived initially and 10.3 per cent were ultimately discharged well.

The initial survival rate and discharge rate in this study correlates fairly well with that of Johnson et al., ${ }^{4}$ where the initial survival rate was 31.7 per cent and final discharge rate was 14.9 per cent. As with our report, Johnson et al. did not report strict criteria for determining a cardiac arrest. Saphir, ${ }^{6}$ who reported an overall discharge rate of 8 per cent, arrived at his figure by excluding all of the patients who did not fit the criteria given below.

"Circulatory arrest is defined as cessation of effective cardiac contractions, resulting in total loss of major pulse, unconsciousness, dilated pupils and death unless the process is reversed: initially spontaneous respiration may be unaffected." However, when the initial event is cessation of respiration, it is logical to assume that circulatory arrest will soon follow.

Results from a 415-bed non-university hospital ${ }^{5}$ show a discharge rate of 26 per cent for one year and 19 per cent for the next. These arrests conform to Saphir's criteria, and the higher success rate may be attributed to the smaller size of the hospital.

Not all of the hospital personnel who may be in a position to initiate cardiopulmonary resuscitation, can be expected to have achieved the necessary clinical sophistication to satisfy Saphir's criteria. In other words, when a "false alarm" is sounded, we do not discourage the initiator of the call, as we would rather have an occasional false alarm and keep our hospital personnel alert to the possibility of being able to save a patient. There should be no reticence among the staff because of fear of being reprimanded for calling an arrest where the diagnosis is in doubt. Therefore, a certain amount of flexibility of criteria should be accepted in any study of this nature. In support of this is the fact that, aside from Kouwenhoven's original study, ${ }^{7}$ there has been very little variation in success rates between so-called controlled and uncontrolled retrospective studies to date.

Key factors in successful resuscitation appear to be: (a) awareness and ability of various hospital personnel to recognize an arrest and to quickly initiate resuscitation procedures, $(b)$ immediate availability of resuscitation equipment for definitive treatment in cardiorespiratory arrest. To these ends, training of hospital personnel and judicious placement of resuscitation equipment appears to be of paramount importance.

At the Toronto General Hospital, the entire nursing staff attends a short annual refresher course in the pathophysiology and technical aspects of cardiopulmonary resuscitation. At these sessions actual practice on the resuscitation manikin is carried out by each nurse. Inhalation therapists are also instructed and serve on the cardiac arrest team. Other paramedical personnel who are trained include: hospital assistants, nursing assistants, ward helpers, physical and occupational therapists, X-ray and laboratory technicians, and dieticians. The whole programme involves training 1,300 people annually. 
As it would not be economically feasible to have an expensive resuscitation cart on every floor, each floor has been stocked with a smaller emergency box which has various drugs, intravenous equipment, and intubation equipment. Emergency oxygen equipment is also kept on each floor. Maintenance of the contents of these boxes is the responsibility of the Inhalation Therapy Department. Drugs and equipment in these boxes are periodically reviewed by members of the Cardiopulmonary Resuscitation Committee. A list of the contents of these boxes is appended (Appendix A).

The placement of the resuscitation carts within the hospital has come about as a direct result of meticulous study of the geographical location of the majority of the arrests within the hospital. For example, a cart has been placed in the area where most of the patients with myocardial infarctions and cardiovascular surgery are convalescing. One group of figures for another hospital shows that patients with the discharge diagnosis of acute myocardial infarction have thirteen times as great a chance of having a cardiac arrest as adult patients with all other discharge diagnoses. The proximity of elevators and stairs is also considered in the placement of the carts. The "acute areas" have received priority for the location of the carts and each has a complete resuscitation cart of its own.

At the end of each arrest the anaesthetist reports on the cardiopulmonary resuscitation form any specific problems with equipment and team mobilization that may have occurred. Many improvements in the technical aspects of cardiopulmonary resuscitation have come from day-to-day review of this part of the report.

It is planned eventually to work out an arrest report which is simple enough for quick completion, but conclusive enough to point toward future improvements in the overall function of the cardiac arrest team. Ideally, a method of reporting data on these forms will be adaptable for inclusion in a data processing system. To this end a new form has been devised (Appendix B) which hopefully will give pertinent data more succinctly. We feel that the ultimate use of the report form will not be as a repository of data for detailed analysis of cardiac or pulmonary pathology, as the information included in this type of arrest form would be too cumbersome for practical completion at the time of arrest. We also feel that such a form should not be used for analysis of drug efficacy, as conclusions inferred from such a study from this form may be dangerously misleading. Because each arrest seems to have its own peculiar set of circumstances, physiological changes often occur with such rapidity that interpretation of treatment data is difficult. This type of assessment requires separate protocol.

\section{Summary}

One hundred and eight-four cardiopulmonary resuscitation reports covering one year at the Toronto General Hospital have been reviewed and statistically analysed, as a means of evaluating the service given by the cardiac arrest team. In the year reviewed the immediate survival rate was 37.3 per cent, but only 10.3 per cent of the patients resuscitated left hospital well. Parameters of location, age, sex, cause, recognition, and time between recognition and initiation of 
resuscitation procedures have been examined. The main determinants of success appear to be the manner of recognition and the speed with which cardiopulmonary resuscitation was initiated.

We reaffirm the necessity for continuing training of all hospital personnel, and have suggested some parameters for the strategic location of equipment, based on evaluation of high risk areas within the hospital.

\section{RÉSUMÉ}

Comme moyen d'évaluer le rendement de l'équipe des arrêts cardiaques, on a passé en revue et analysé au point de vue statistiques 184 rapports de réanimation cardio-pulmonaire couvrant une période d'un an au Toronto General Hospital. Durant l'année qui nous intéresse, la survie immédiate a été de 37.3 pour cent, mais 10.3 pour cent seulement des malades réanimés ont quitté l'hôpital en bonne santé. On a examiné les paramètres de lieu, d'âge, de sexe, de cause, le diagnostic et le temps écoulé entre le diagnostic et le début des procédés de réanimation. Les facteurs déterminants de succès semblent être la précocité du diagnostic.et la célérité avec laquelle on a commencé la réanimation.

Nous insistons de nouveau sur l'entrainement continu de tout le personnel de l'hôpital, et nous avons suggéré que le matériel soit placé en un endroit statégique, basé sur les zones de l'hôpital où sont concentrés les risques les plus élevés.

\section{REFERENCES}

1. McMillan, R. L.; Brown, K. W. G.; Peckram, G. B.; Kahn, O.; Hutchinson, D. B.; \& Paton, M. Changing Perspectives in Coronary Care. Am. J. Cardiol. 20: 451 (1967).

2. Lown, B, Intensive Heart Care. Sc. Amer. 219: 19 (1968).

3. Hollingsworth, J. H. The Result of Cardiopulmonary Resuscitation: A Three Year University Hospital Experience. Ann. Int. Med. 71: 459 (1969).

4. Johnson, A. L.; TANser, P. H.; Ulan, R. A.; \& Wood, T. E. Results of Cardiac Resuscitation in 552 Patients. Am. J. Cardiol. 20: 831 (1967).

5. Unpublished Data from Analysis of Coded Diagnoses - Union Memorial Hospital, Baltimore, Maryland (July 1968-June 1969).

6. SAPHIR, R. External Cardiac Massage: Prospective Analysis of 123 Cases and Review of the Literature. Medicine (Baltimore). 47: 73 (1968).

7. Kouwenhoven, W. B.; Jude, J. R.; \& Knickerbocker, G. G. Closed Chest Cardiac Massage. J.A.M.A. 173: 1064 (1960).

APPENDIX A

Toronto General Hospital Emergency Kit-Contents

\begin{tabular}{|c|c|}
\hline Equipment & Drugs \\
\hline $\begin{array}{l}\text { 1. pulmonator bag } \\
\text { 2. facepiece to fit above } \\
\text { 3. orotracheal airway-size } 3 \\
\text { 4. one each sterile } 5 \mathrm{ml} \& 10 \mathrm{ml} \text { syringe } \\
\text { 5. one each no. } 15 \text { \& no. } 18 \text { needles } \\
\text { 6. two no. } 21 \text { spinal needles }-5^{\prime \prime} \text { long } \\
\text { 7. metal suction tip for oral suction } \\
\text { 8. one no. } 28 \text { safety check i.v. set } \\
\text { 9. one no. } 16 \text { argyle i.v. cannula } \\
\text { 10. one no. } 18 \text { argyle i.v. cannula } \\
\text { 11. penrose tubing } \\
\text { 12. one blood testing package } \\
\text { 13. one no. } 16 \text { Toronto endobronchial } \\
\text { catheter (long) }\end{array}$ & $\begin{array}{l}\text { 1. } 2 \text { vials succinylocholine- }-100 \mathrm{mg} / 2 \mathrm{cc} \\
\text { 2. } 1 \text { ampoule atropine sulphate gr } 1 / 100 \\
\text { 3. } 2 \text { ampoule adrenaline HCL-1:100 } \\
\text { 4. } 2 \text { ampoule calcium glucose-10\% } \\
\text { 5. } 4 \text { vials } 1: 5000 \text { isopropylnoradrenaline } \\
\text { 6. } 1-500 \mathrm{ml} \text { bottle sodium bicarbonate } \\
\text { 7. } 1 \text { tube anaesthetic lubricant } \\
\text { Intubation set } \\
\text { 1. endotracheal connector } \\
\text { 2. laryngoscope with spare batteries and bulb } \\
\text { 3. } 1 \text { no. } 8 \text { and } 1 \text { no. } 9 \text { cuffed endotracheal tube } \\
\text { 4. one } 10 \mathrm{mlsyringe,} \mathrm{inflating} \mathrm{cannula,} \mathrm{hemostat} \\
\text { 5. one each no. } 4 \text { and no. } 4 \text { suction } T \text { piece }\end{array}$ \\
\hline
\end{tabular}




\section{APPENDIX B}

\section{CARDIOPLLNONARY RESLSCTTATION REPOLTT}

Date ${ }_{\text {Time __ Age __ Place }} \_$Sex ________

NOTE: Mark all times in minutes from time arrest called.
J. PLACE
(1) E.R.
(2) O.R.
II. FOUND BY
(1) Nurse
(2) Doctor
(3) Monitor
(3) Ward
(4) Other
III. CONDITION WHEN FOUND
(4) Coronary
(1) No respiration
(2) No pulse
(3) Pupils dilated
(4) C.H.F.

Unit

(5) Other

I. C. Us.

IV. TIME LAPSE FROA DISCOVERY TO

(2) Ventilation
(2) Massage min.
(3) I. V.
(4) Defibrin.
min.

VENTILATION

VI. DEFIBRILLATIONS

(4) Defibrilator _ min.

II. LAST KNOWN ECG
(1) Sinus
(2) Noclal
(3) $1^{0} \mathrm{~A}-\mathrm{V}$ block
(4) $2^{0} A-V$ block
(b) V.P.B.S
(6) A.F.
(7) P.A.T.

(1) Mouth to mouth

(2) Bag - mask

(3) Bag - tube

j $\mathrm{ECG}$ after

(4) Ventilator

VIII. INTTLAL ECG

(1) Sinus

(2) A-V dissoc

(3) V.F.

(4) Flat

IX. TERMNAL ECG

(1) Sinus

(2) Paced

(i) V.F.

(4) Flat

(5) A.F.

min. (1) min. (2) min. (3) min. (4)

(a) $\longrightarrow \mathrm{ECG}$ after

(b) j ECG after

(7) $\quad \mathrm{ECG}$ after

(8) — $\longrightarrow$ ECG after

(日) $\quad \mathrm{j}$ ECG after

(i0) — ECG after

$x$ DRUG THERAPY

(1) Epinephrine (1 mg

(2) $\mathrm{Ca}^{++}$Gluconate $\mathrm{A} \mathrm{gm}$ )

(3) $\mathrm{NaHCO}_{3}$ (no. of $50 \mathrm{cc}$ )

(4) $\mathrm{NaHCO}_{3}$ (no. of

I. RESUSCITATION STOPPED

(1) RFASON FO

(2) Procedure inappropriate

i. terminal disease

ii. delay in starting

(5) Isuprel (Bolus)

(6) Xyloca ine (Bolus)

(7) Other

(3) Other After min.

III. IMM EDIATE FOLLOWUP

(1) Medications I. V

(2) Disposition

(3) Primary diagnosis

(4) Equipment function

(j) Remaiks

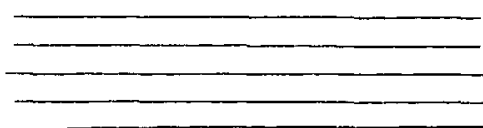

XIV. SUSPECTED CAUSE OF ARREST

(3) Patient stable

(3) Pati

ii. P Pupils (L) dilated Drip Drip

NG PROCEDURE

i. (2) constricted

iv. Spontaneous respiration (1)es

v. Intubaled (1) Yes (2) $\mathrm{No}$

vi. Conscious (1) Yes (2) No

(1) Myocardial infarct ____ (6) Hemorrhage

(2) Pulmonary oedema__ (7) Respiratory

(3) Pulmonary embolus

(4) Anaesthesia Obstruction

(5) Drug

(8) Other

Signed M. D.

R. N. 